\title{
Etiology of urinary tract infection and drug resistance cases of uropathogenes
}

\author{
Bhatt CP1, 2, Shrestha $B^{3}$, Khadka $S^{2}$, Swar $S^{2}$, Shah B ${ }^{2}$, Pun $K^{2}$ \\ ${ }^{1}$ Associate Professor, Department of Microbiology, Kathmandu Medical College Teaching Hospital, Kathmandu, Nepal \\ ${ }^{2}$ Nobel College, Kathmandu, Nepal, ${ }^{3}$ Microbiologist, Kathmandu Model Hospital, Kathmandu, Nepal
}

\section{Abstract}

Background: Multidrug resistant bacterial isolates have been frequently reported from different parts of the world as emerging treatment problem.

Objectives: The study was conducted to find out etiology of urinary tract infection and drug resistance trend among clinical pathogens in urinary tract.

Methods: Mid-stream urine samples from patients suspected of urinary tract infection were collected for routine culture and antibiotic susceptibility testing and were processed according to the standard laboratory methods.

Results: In this study $41.7 \%$ urine samples showed significant bacterial growth. Gram negative bacteria were the predominant organisms. Among them Escherichia coli was the predominant isolate (85.1\%) whereas Enterococcus faecalis $(40.6 \%)$, was the major Gram positive isolate. Among culture positive cases organisms were isolated in highest frequency (29.5\%) in the age group 21 to 30 years. Urinary tract infections were found more common in females $(61.1 \%)$ than in males (38.9\%). Nitrofurantoin (82.2\%) and Ofloxacin (57.8\%) were found to be the most effective drugs against Gram negative organisms, whereas for Gram positive organisms, Nitrofurantoin (87.5\%) and Gentamycin (78.1\%) were found to be the most effective drugs. Escherichia coli was found sensitive to Nitrofurantoin (89.3\%) followed by Ofloxacin (63.3\%). Enterococcus faecalis was most susceptible to Nitrofurantion (92.3\%) followed by Cotrimoxazole (76.9\%).

Conclusion: In this study, among the participants $41.7 \%$ had culture positive urinary tract infection. Drug resistance was found to be high in both Gram negative and Gram positive organisms. The high prevalence of drug resistance among urinary tract infection patients calls for the need of judicious measures for control of this infection and knowledge of patterns of resistance helps in deciding empirical therapy for urinary tract infection.

Key words: E. coli, MDR, Urinary tract infection

\section{INTRODUCTION}

$I^{2}$ the recent years, incidence of multidrug resistance in pathogenic and opportunistic bacteria has been increasingly documented'. These multidrug-resistant bacteria have also created immense clinical problems in cancer and immune compromised patients. Most important multidrug-resistant bacteria on the global scale include Gram-positive (methicillin-resistant Staphylococcus aureus (S. aureus), vancomycin-resistant Enterococci) and Gram-negative bacteria (members of enterobacteriaceae producing plasmid-mediated extended spectrum $\beta$-lactamase (ES $\beta \mathrm{L})$ ) and others like Pseudomonas aeruginosa ( $P$. aeruginosa), Mycobacterium

\footnotetext{
Address for correspondence

Dr. Chandra Prakash Bhatt

Associate Professor

Department of Microbiology, Kathmandu Medical College Teaching Hospital, Kathmandu, Nepal

E-mail:drcpbhatt@yahoo.com,drcpbhatt@gmail.com
}

tuberculosis². Careless and injudicious use of antibiotics as well as empirical antimicrobial therapy has been the major contributing factor in the emergence of multi drug resistant bacteria. Antibiotic resistance has been an emerging problem in the world ${ }^{3}$.

Urinary tract infection (UTI) is a common bacterial disease, often contributing to frequent morbidity in out-patients as well as hospitalized patients ${ }^{4}$. Clinical experience has indicated the presence of numerous cases of antibiotic resistance to common antibiotics by uro-pathogens in both developed and developing countries 5 . Resistances to newer and more potent antimicrobials are no exceptions, making therapeutic options very limited to certain antimicrobial agents like Carbapenem, Colistin and Fosfomycin ${ }^{6}$.

Tabiban et al conducted a study to assess the association between host characteristics and uropathogens in USA 
and found that $P$. aeroginosa can cause UTI to those patients who have undergone urinary tract procedures ( $43 \%$ versus $15 \%$ overall), have a neurogenic bladder ( $29 \%$ versus $12 \%$ overall), have received recent antibiotic therapy ( $52 \%$ versus $24 \%$ overall), and a male ( $76 \%$ versus $28 \%$ overall). Proteus mirabilis (P. mirabilis) can cause UTI primarily to those patients who have a foreign body in the lower urinary tract $(48 \%$ versus $30 \%$ overall) 7 . Amiri et al performed a study in Iran to assess an association between hygiene practices and sexual intercourse to UTI and found that sexual intercourse $\geq 3$ times per week (Odds Ratio, OR: 5.62), recent UTI (OR: 3.27), not washing genitals pre-coitus (OR: 2.89 ), not voiding urine post-coitus (OR: 8.62 ) and washing genitals from back to front (OR: 2.96) were found to be associated with UTI ${ }^{8}$. Antimicrobial therapy of UTI caused by Escherichia coli (E. coli) is often impaired due to the resistance to commonly used antimicrobial agents ${ }^{6,9}$. E. coli has been reported to be MDR by possessing the antibiotic resistant genes in its transferable R-plasmid ${ }^{10}$.

Updated knowledge of causal bacteria and their susceptibility patterns are important for proper selection and use of antibiotics as well as for an appropriate prescribing policy. The aim of this study was to determine drug resistant urinary pathogens, knowledge of which could be helpful in formulating and monitoring the antibiotic policy and proper empirical therapy.

\section{METHODS}

A descriptive study was conducted from July 2011 to November 2011. The study included all patients suspected of urinary tract infection who visited outpatient department (OPD) and inpatient department. The research objective and methods were explained to the patients and informed consent was obtained from each of them before collection of specimen. In this study mid-stream urine samples from 996 patients suspected of urinary tract infection were collected for routine culture and antibiotic susceptibility testing and were processed according to the standard laboratory methods. The urine samples were cultured onto MacConkey agar and blood agar plates by the semi-quantitative culture technique using a standard calibrated loop. Known volume $(0.001 \mathrm{ml})$ of mixed uncentrifuged urine was innoculated on the surface of MacConkey agar (MA) and blood agar (BA). The plates were then aerobically incubated at $37^{\circ} \mathrm{C}$ overnight. Colony count was performed to calculate the number of colony forming units (CFU) per $\mathrm{ml}$ of urine and the bacterial count was reported as: $<10^{4} / \mathrm{ml}$ organisms: not significant; $10^{4}$ to $10^{5} / \mathrm{ml}$ organisms: doubtful significance (suggest repeat specimen); $>10^{5} / \mathrm{ml}$ organisms: significant bacteriuria.
The identification of bacterial isolates was done using standard microbiological techniques as described in Bergey's Manual of Systemic Bacteriology ${ }^{11}$ which comprises of studying the colony characters, staining reactions and biochemical tests. Antibiotic susceptibility test of different isolates were performed by Kirby-Bauer disk diffusion method on Mueller Hinton agar (MHA). The antibiotic discs used for the susceptibility tests were from Hi-Media Laboratories Private Limited and included Amoxicillin $(10 \mu \mathrm{g})$, Cefixime $(5 \mu \mathrm{g})$, Cefotaxime $(30 \mu \mathrm{g})$, Ciprofloxacin $(5 \mu \mathrm{g})$, Cotrimoxazole $(25 \mu \mathrm{g})$, Erythromycin $(15 \mu \mathrm{g})$, Nitrofurantoin $(300 \mu \mathrm{g})$, Norfloxacin $(10 \mu \mathrm{g})$ and Ofloxacin $(5 \mu \mathrm{g})$. Data was analyzed by EPI-Info version 3.3.2, document version 8.08 (updated September 2005).

\section{RESULTS}

Out of 996 urine samples proceeded; 416 (41.7\%) samples showed significant bacterial growth, among them 384 isolates were Gram negative and 32 were Gram positive organisms (Figure 1).

Among Gram negative isolates, E. coli was the predominant isolate $(85.1 \%)$ followed by $C$. freundii (8.3\%), E. aerogenes (2\%), C. diversus (1.3\%), P. aeruginosa (1\%), P. mirabilis (1\%), whereas E. faecalis $(40.6 \%)$, CoNS $(37.5 \%)$, S. aureus (12.5\%), Beta haemolytic streptococci (9.3\%) were Gram positive isolates (Table 1).

\section{Table 1: Species wise distribution of uro-pathogens}

\begin{tabular}{|c|c|c|}
\hline Uro-pathogens & Number & Percentage \\
\hline Gram negative & 384 & $100 \%$ \\
\hline Escherichia coli (E. coli) & 327 & $85.1 \%$ \\
\hline $\begin{array}{l}\text { Citrobacter freundii (C. } \\
\text { freundii) }\end{array}$ & 32 & $8.3 \%$ \\
\hline $\begin{array}{l}\text { Enterobacter aerogenes (E. } \\
\text { aerogenes) }\end{array}$ & 8 & $2 \%$ \\
\hline $\begin{array}{l}\text { Citrobacter diversus (C. } \\
\text { diversus) }\end{array}$ & 5 & $1.3 \%$ \\
\hline $\begin{array}{l}\text { Pseudomonas aeruginosa ( } \mathrm{P} \text {. } \\
\text { aeruginosa) }\end{array}$ & 4 & $1 \%$ \\
\hline Proteus mirabilis (P. mirabilis) & 4 & $1 \%$ \\
\hline $\begin{array}{l}\text { Klebsiella pneumoniae (K. } \\
\text { pneumoniae) }\end{array}$ & 3 & $0.78 \%$ \\
\hline Proteus vulgaris (P. vulgaris) & 1 & $0.26 \%$ \\
\hline Gram positive & 32 & $100 \%$ \\
\hline $\begin{array}{l}\text { Enterococcus faecalis (E. } \\
\text { faecalis) }\end{array}$ & 13 & $40.6 \%$ \\
\hline $\begin{array}{l}\text { Coagulase negative } \\
\text { Staphylococcus species (CoNS) }\end{array}$ & 12 & $37.5 \%$ \\
\hline $\begin{array}{l}\text { Staphylococcus aureus (S. } \\
\text { aureus) }\end{array}$ & 4 & $12.5 \%$ \\
\hline Beta haemolytic Streptococci & 3 & $9.3 \%$ \\
\hline
\end{tabular}




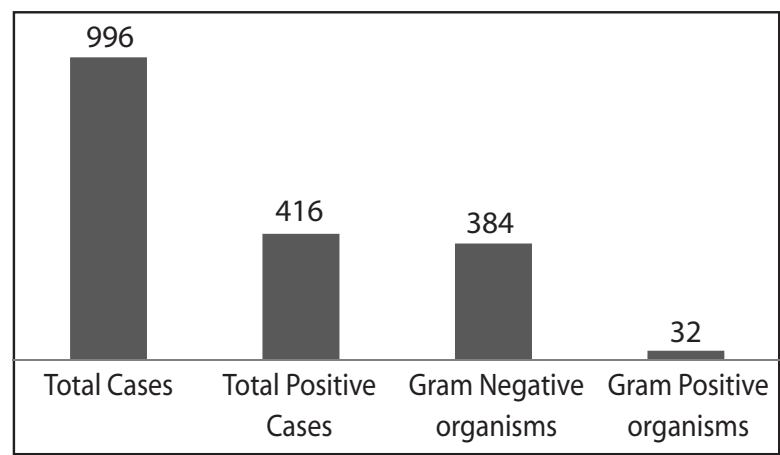

Figure 1: Growth profile and distribution of Gram positive and Gram negative organisms

Table 2: Age and gender wise distribution of uropathogens

\begin{tabular}{ccccc}
\hline Age group & Total no & \multicolumn{4}{c}{ Total number of isolates } \\
${ } }$ & of sample & Male & Female & Total \\
\hline $0-10$ & 59 & 10 & 13 & $23(5.53 \%)$ \\
\hline $11-20$ & 93 & 15 & 32 & $47(11.30 \%)$ \\
\hline $21-30$ & 305 & 47 & 76 & $123(29.57 \%)$ \\
\hline $31-40$ & 174 & 31 & 58 & $89(21.39 \%)$ \\
\hline $41-50$ & 131 & 21 & 36 & $57(13.70 \%)$ \\
\hline $51-60$ & 77 & 16 & 20 & $36(8.65 \%)$ \\
\hline $61-70$ & 80 & 17 & 10 & $27(6.49 \%)$ \\
\hline $71-80$ & 77 & 5 & 9 & $14(3.36 \%)$ \\
\hline
\end{tabular}

Maximum number of culture positive cases (29.57\%) belonged to the age group 21 to 30 years followed by age group 31 to 40 years (21.39\%) and age group 41 to 50 years $(13.70 \%)$.

Table 3 shows antibiotic resistance pattern of different Gram negative isolates. E. coli was found susceptible to
Nitrofurantoin (89.3\%), followed by Ofloxacin (63.3\%). Ofloxacin $(71.8 \%)$ was the most effective antibiotics against $C$. freundii followed by Norfloxacillin and Cotrimoxazole (34.3\%). C. diversus showed maximal susceptibility $(100 \%)$ to Ciprofloxacin, Norfloxacin, and Ofloxacin followed by Cotrimoxazole, Nitrofurantoin, Cefotaxime and Cefixime (60\%). E. aerogenes showed $75 \%$ sensitivity to Nitrofurantoin followed by Norfloxacin, Ofloxacin and Cefixime (62.5\%). P. aeruginosa was susceptible to majority of antibiotics. It was $100 \%$ sensitive to Ciprofloxacin, Cefotaxime, Ceftriaxone, Gentamycin and $100 \%$ resistant to Cefixime and Cotrimoxazole. Isolates of $P$. mirabilis were found to be $100 \%$ susceptible against Norfloxacin. In K. pneumoniae, the most effective antibiotics were Ciprofloxacin, Cefotaxime, Norfloxacin and Ofloxacin (100\%) followed by Cotrimoxazole (66.6\%). P. vulgaris was $100 \%$ susceptible to Cotrimoxazole, Cefotaxime, Cefixime, Norfloxacin.

Table 4: Antibiotic susceptibility pattern of overall Gram negative bacilli

\begin{tabular}{lcccc}
\hline Antibiotic & \multicolumn{2}{c}{ Sensitive } & \multicolumn{2}{c}{ Resistant } \\
& $\mathrm{N}$ & $\%$ & $\mathrm{~N}$ & $\%$ \\
\hline Amoxycillin & 200 & $52.1 \%$ & 184 & $47.9 \%$ \\
\hline Cotrimoxazole & 193 & $50.3 \%$ & 191 & $49.7 \%$ \\
\hline Ciprofloxacin & 209 & $54.4 \%$ & 175 & $45.6 \%$ \\
\hline Cefotaxime & 203 & $52.9 \%$ & 181 & $47.1 \%$ \\
Cefixime & 191 & $49.7 \%$ & 193 & $50.3 \%$ \\
\hline Norfloxacin & 211 & $54.9 \%$ & 173 & $45.1 \%$ \\
Ofloxacin & 222 & $57.8 \%$ & 162 & $42.2 \%$ \\
\hline Nitrofurantoin & 316 & $82.3 \%$ & 68 & $17.7 \%$ \\
\hline
\end{tabular}

For Gram negative isolates, 8 different antibiotics were tested. Among them Nitrofurantoin was found

Table 3: Antibiotic resistance pattern of Gram negative bacteria

\begin{tabular}{|c|c|c|c|c|c|c|c|c|}
\hline Antibiotic & $\begin{array}{c}\text { Escherichia } \\
\text { coli } \\
n=327\end{array}$ & $\begin{array}{c}\text { Citrobacter } \\
\text { freundii } \\
n=32\end{array}$ & $\begin{array}{c}\text { Citrobacter } \\
\text { diversus } \\
\text { n=5 }\end{array}$ & $\begin{array}{c}\text { Enterobacter } \\
\text { aerogenes } \\
\qquad \mathbf{n = 8}\end{array}$ & $\begin{array}{c}\text { Pseudomonas } \\
\text { aeruginosa } \\
\text { n=4 }\end{array}$ & $\begin{array}{c}\text { Proteus } \\
\text { mirabilis } \\
n=4\end{array}$ & $\begin{array}{c}\begin{array}{c}\text { Klebsiella } \\
\text { pneumoniae }\end{array} \\
\text { n=3 }\end{array}$ & $\begin{array}{c}\begin{array}{c}\text { Proteus } \\
\text { vulgaris } \\
n=1\end{array}\end{array}$ \\
\hline Amoxycillin & $82.5 \%$ & $96.8 \%$ & $100 \%$ & $100 \%$ & $50 \%$ & $75 \%$ & $100 \%$ & $100 \%$ \\
\hline Cotrimoxazole & $42.2 \%$ & $65.6 \%$ & $40 \%$ & $50 \%$ & $100 \%$ & $25 \%$ & $33.3 \%$ & $0 \%$ \\
\hline Ciprofloxacin & $48.8 \%$ & $71.8 \%$ & $0 \%$ & $62.5 \%$ & $0 \%$ & $100 \%$ & $0 \%$ & $100 \%$ \\
\hline Cefotaxime & $43.1 \%$ & $81.2 \%$ & $40 \%$ & $50 \%$ & $0 \%$ & $25 \%$ & $0 \%$ & $0 \%$ \\
\hline Cefixime & $51.3 \%$ & $84.3 \%$ & $40 \%$ & $37.5 \%$ & $100 \%$ & $25 \%$ & $66.6 \%$ & $0 \%$ \\
\hline Norfloxacin & $59.6 \%$ & $65.6 \%$ & $0 \%$ & $37.5 \%$ & $0 \%$ & $0 \%$ & $0 \%$ & $0 \%$ \\
\hline Ofloxacin & $36.7 \%$ & $28.1 \%$ & $0 \%$ & $37.5 \%$ & $0 \%$ & $25 \%$ & $0 \%$ & $0 \%$ \\
\hline Nitrofurantoin & $10.7 \%$ & $78.1 \%$ & $40 \%$ & $25 \%$ & $75 \%$ & $100 \%$ & $66.6 \%$ & $100 \%$ \\
\hline
\end{tabular}


Table 5: Antibiotic resistance pattern of Gram positive organisms

\begin{tabular}{lcccc}
\hline Antibiotic & $\begin{array}{c}\text { Enterococcus faecalis } \\
\text { Gentamycin }\end{array}$ & $\begin{array}{c}\text { Coagulase negative } \\
\text { staphylococci } \\
\mathbf{n = 1 3}\end{array}$ & $\begin{array}{c}\text { Staphylococcus } \\
\text { aureus } \\
\mathbf{n = 4}\end{array}$ & $\begin{array}{c}\text { Beta haemolytic } \\
\text { Streptococci } \\
\mathbf{n = 3}\end{array}$ \\
Norfloxacin & $38.4 \%$ & $25 \%$ & $25 \%$ & $0 \%$ \\
Amoxycillin & $61.5 \%$ & $33.3 \%$ & $75 \%$ & $66.6 \%$ \\
Cefotaxime & $61.5 \%$ & $50 \%$ & $0 \%$ & $66.6 \%$ \\
Cotrimoxazole & $53.8 \%$ & $25 \%$ & $0 \%$ & $66.6 \%$ \\
Ciprofloxacin & $23 \%$ & $0 \%$ & $25 \%$ & $33.3 \%$ \\
Nitrofurantoin & $61.5 \%$ & $8.3 \%$ & $100 \%$ & $66.6 \%$ \\
\hline Erythromycin & $7.7 \%$ & $33.3 \%$ & $75 \%$ & $0 \%$ \\
\hline
\end{tabular}

to be the most effective (82.2\%) followed by Ofloxacin (57.8\%), Norfloxacin (54.9\%), whereas most isolates were resistant to Cefixime (50.2\%) and Cotrimoxazole (49.7\%) (Table 4).

Table 5 shows the antibiotics susceptibility pattern of Gram positive organism. E. faecalis was found $92.3 \%$ sensitive to Nitrofurantoin followed by Cotrimoxazole (76.9\%). In Coagulase negative staphylococci showed $100 \%$ sensitivity to Nitrofurantoin followed by Gentamycin (91.6\%). S. aureus was 100\% sensitive to Norfloxacin, Amoxycillin and Nitrofurantoin. Beta haemolytic Streptococci showed $100 \%$ sensitivity to Amoxicillin, Gentamycin and Nitrofurantoin.

Table 6: Antibiotic susceptibility pattern of overall Gram positive cocci

\begin{tabular}{lcccc}
\hline & \multicolumn{2}{c}{ Sensitive } & \multicolumn{2}{c}{ Resistant } \\
\hline \multicolumn{1}{c}{ Antibiotic } & Number & $\%$ & Number & $\%$ \\
Cephalexin & 21 & $65 \%$ & 11 & $35 \%$ \\
\hline Gentamycin & 25 & $78.1 \%$ & 7 & $21.9 \%$ \\
\hline Erythromycin & 14 & $43.8 \%$ & 18 & $56.2 \%$ \\
\hline Norfloxacin & 15 & $46.9 \%$ & 17 & $53.1 \%$ \\
\hline Amoxycillin & 22 & $68.8 \%$ & 10 & $31.2 \%$ \\
\hline Cefotaxime & 19 & $59.4 \%$ & 13 & $40.6 \%$ \\
\hline Cotrimoxazole & 20 & $62.5 \%$ & 12 & $37.5 \%$ \\
\hline Ciprofloxacin & 18 & $56.3 \%$ & 14 & $43.7 \%$ \\
\hline Nitrofurantoin & 28 & $87.5 \%$ & 4 & $12.5 \%$ \\
\hline
\end{tabular}

Among the nine different antibiotics tested against Gram positive isolates, Nitrofurantoin was found to be the most effective (87.5\%) sensitivity, followed by Gentamycin (78.1\%), Amoxycilin (68.8\%), Cephalexin (65\%), Cotrimoxazole (62.5\%), Cefotaxime (59.4\%) and Ciprofloxacin (56.3\%) (Table 6).

\section{DISCUSSION}

Antimicrobial resistance is a global problem. It is now accepted as a major public health issue and has significant implication on health and patient care. Resistance to antimicrobial drugs is associated with high morbidity and mortality, high health-care cost and prolonged hospitalization. The problem of antimicrobial resistance is more troublesome to developing countries. World Health Organization (WHO) and the European Commission (EC) have recognized the importance of studying the emergence and determinants of resistance and the need for strategies for its control. Microorganisms and their resistance patterns vary from hospital to hospital and even from clinic to clinic in the same hospital.

The findings of present study showed that $41.7 \%$ urine samples showed significant bacterial growth. A similar study carried out by Chhetri et al also showed low number of growth positivity ${ }^{12}$. In this study, UTI was found to be more common in female $(61.1 \%)$ than male (38.9\%). Previous study done by Jha and Bapat ${ }^{13}$, Aiyegoro et al also found similar results. This suggests that the incidence of urinary tract infection was higher in females than males which was found statistically significant $(p<0.05)^{14}$. The higher incidence of urinary tract infection in females might be the result of a variety of factors, such as shorter urethra and closer proximity to the anus.

In culture positive cases the age group of 21 to 30 years had higher prevalence of UTI (29.57\%). This age group is more sexually active and chances are high that they suffer from UTI. Previous study done by Steenberg et $\mathrm{al}^{15}$, Rajbhandari and Shrestha ${ }^{16}$ also found similar results. Leigh had found that Nuns and unmarried women have lower prevalence of UTI as compared to married women ${ }^{17}$. Out of 416 uro-pathogens, 384 (92.3\%) were Gram negative bacilli and 32 (7.6\%) were Gram positive cocci. Higher frequency of $E$. coli in this study resembles to the various studies done by different scientists in different parts of the world ${ }^{20-22}$. In a similar study 
conducted by Das et $\mathrm{al}^{23}$ among the total isolates, $94.5 \%$ were Gram negative bacilli and 5.5\% were Gram positive cocci which revealed that UTI is primarily caused by Gram negative bacteria. This finding agrees with studies done in the other parts of the world 24,25 . Okada et al also found 70.2\% Gram negative bacilli and 29.8\% Gram positive isolates ${ }^{26}$. Similarly in a study done by Obi et al in Africa among 10 species of bacteria, the distribution of Gram negative and Gram positive bacteria were $88.5 \%$ and 9.7\% respectively in UTI positive sample. This finding suggests the source of the infecting organisms is usually the faecal flora of the patients ${ }^{27}$. In a similar study done by Levett in India ${ }^{18}$ and Karki et al in Kathmandu higher percentage of Gram negative rods were found ${ }^{19}$.

In our study, among the various drugs used against Gram negative isolates, Nitrofurantoin followed by Ofloxacin with susceptibility of $82.2 \%$ and $57.8 \%$ respectively were found to be the most effective drugs. Similar results were obtained in the study conducted by Gales et $\mathrm{al}^{28}$.

Of the nine different antibiotics used against Gram positive isolates, Nitrofurantoin (87.5\%), Gentamycin (78.1\%) Amoxicillin (68.7\%), Cephalexin (65\%), Cotrimoxazole (62.5\%), Cefotaxime (59.3\%), Ciprofloxacin (56.2\%), Norfloxacin (46.8\%) and Erythromycin (43.7\%) were the most effective drugs. Erythromycin was found to be least effective against Gram positive isolates (susceptibility was $43.7 \%$ ). Similar study conducted by Abubakar ${ }^{31}$ found higher resistance than this study the mean sensitivity of the antibiotics were Ofloxacin (63.8\%), Ampicillin (25.4\%), Nitrofurantoin (55.4\%), Cotrimoxazole (41.8\%), and Erythromycin (51.6\%). In this study, among Gram positive organisms E. feacalis was the most common isolate. Sensitivity to Nitrofurantoin, Cotrimoxazole and Gentamycin were $92.3 \%, 76.9 \%$ and $61.5 \%$ respectively.

E. coli, was the most common isolate, Nitrofurantoin $(89.3 \%)$ was found to be the most effective drug followed by Ofloxacin (63.3\%), Ciprofloxacin (58.1\%) and Cotrimoxazole (58.1\%). Study conducted by Baral et al ${ }^{32}$ showed that resistance to Nitrofurantion was similar to this study (17.6\%) but study conducted by Abubakar ${ }^{31}$ found resistance higher than this study. Mutations at the target site i.e. gyrA, which is a gyrase subunit gene, and parC, which encodes a topoisomerase subunit, confer resistance to fluoroquinolones ${ }^{29}$. In addition to this mechanism, there are more than seven efflux systems in E. coli that can export structurally unrelated antibiotics; these multidrug resistance efflux pump (MDR pump) systems contribute to intrinsic resistance for toxic compounds such as antibiotics, antiseptics, detergents, and dyes ${ }^{30}$. Higher resistance rate is seen in tertiary hospitals especially where both inpatient and outpatients are present. It may be due to those patients having more complicated UTIs and thus exposed to more resistant flora, or may have failed previous therapy, all of which may account for the increased resistance observed.

A large number of the bacterial isolates in this study showed multiple antibiotic resistances. The present study data gives an idea about the trend of increasing antibiotic resistance of uropathogens in UTI, which may be due to many factors including misuse of antibiotics by the health care professionals or non-skilled practitioners, misuse of antibiotics by the general public (antibiotics can be purchased in Nepal without a prescription), and inadequate surveillance due to lack of information arising from routine antimicrobial susceptibility testing. The discovery and development of antibiotics is undoubtedly one of the greatest advances of modern medicine. Unfortunately the emergence of antibiotic resistance bacteria is threatening the effectiveness of many antimicrobial agents which has increased the hospital stay of the patients which in turn causes economic burden.

\section{CONCLUSION}

The prevalence of UTI was found comparatively higher in female patients than in male patients and Gram negative organisms were found predominant. The high prevalence of drug resistance among UTI patients calls for the need of judicious measures for control of this infection and knowledge of patterns of resistance helps in deciding empirical therapy for UTI. 


\section{REFERENCES}

1. Jones ME, Draghi DC, Thornsberry C, Karlowsky JA, Sahm DF, Wenzel RP. Emerging resistance among bacterial pathogens in the intensive care unit - a European and North American Surveillance study (2000-2002). Ann Clin Microbiol Antimicrob. 2004;3:14.

2. Sajduda A, Dziadek J, Dela A, Zalewska-Schonthaler $\mathrm{N}$, Zwalska Z, Fadden JMC. DNA finger printing as an indicator of active transmission of multi drugresistant Tuberculosis in Poland. Int J Infect Dis. 1998;3:12-7.

3. Khan AU, Zaman MS. Multiple drug resistance pattern in Urinary Tract Infection patients in Aligarh. Biomed Res. 2006;17(3):179-81.

4. Wagenlehner FM, Naber KG. Treatment of bacterial urinary tract infections: presence and future. Eur Urol. 2006;49(2):235-44.

5. Gupta K. Addressing antibiotic resistance. Am J Med. 2002;113(Suppl 1A):S29-34.

6. Giamarellou H. Multidrug-resistant Gram-negative bacteria: how to treat and for how long. Int J Antimicrob Agents. 2010;36(Suppl 2):S50-4.

7. Tabibian JH, Gornbein J, Heidari A, Dien SL, Lau VH, Chahal $P$, et al. Uropathogens and host characteristics. J Clin Microbiol. 2008;46(12):3980-6.

8. Amiri FN, Rooshan MH, Ahmady MH,Soliamani MJ. Hygiene practices and sexual activity associated with urinary tract infection in pregnant women. La Revue de Santé de la Méditerranéeorientale. 2009;15(1):104-10.

9. Chakupurakal R, Ahmed M, Sobithadevi DN, Chinnappan S, Reynolds T. Urinary tract pathogens and resistance pattern. J Clin Pathol. 2010;63(7):6524.

10. Vaidya VK. Horizontal transfer of antimicrobial resistance by extended-spectrum beta lactamaseproducing Enterobacteriaceae. J Lab Physicians. 2011;3(1):37-42.

11. George MG, David RB, Richard WC. Bergey's Manual of Systematic Bacteriology 2nd ed. Springer, NY; 2001.

12. Chhetri PK, Rai SK, Pathak UN, Thapa JB, Devkota KC, Shrestha BO, Shrestha RR. Retrospective study on urinary tract infection at Nepal Medical College Teaching Hospital. Nepal Med Coll J. 2001;3:83-5.

13. Jha N, Bapat SK. A study of sensitivity and resistance of pathogenic micro organisms causing UTI in Kathmandu valley. Kathmandu Univ Med J.2005;3(2):123-9.

14. Aiyegoro OA, Igbinosa OO, Ogunmwonyi IN, Odjadjare $\mathrm{EE}$, Igbinosa $\mathrm{OE}$, Okoh Al. Incidence of urinary tract infections (UTI) among children and adolescents in Ile-Ife, Nigeria. Afr J Microbiol. 2007;1:13-8.

15. Steenberg J, Bartels ED, Bay-Nielsen H. Epidemiology of urinary tract diseases in general practice. BMJ. 1985;4:390.

16. Rajbhandari R, Shrestha J. Bacteriological study of urinary tract infection and its antibiotic sensitivity test (Hospital based study). J Nepal Assoc Med Lab Sci. 2002;4(4):26-32.

17. Topley and Wilson's Principles of Bacteriology, Virology and immunity, bacterial diseases, 8th ed. Frome and London: Butler and Tanner Ltd; 1990. 197-214.

18. Levett PN. Analysis of pathogens isolated from urinary tract infection in Barbados. West Indian Med J.1993;42:72-76.

19. Karki A, Tiwari BR, Pradhan SB. Study of Bacteria isolated from Urinary tract infection and their sensitivity Pattern. J Nepal Med Assoc. 2004;43:200-3.

20. Dhakal BK, Pokhrel BM, Ahnn J. Microscopic detection of urinary tract infection in Nepalese patients. J Microbiol.2002;40(4):267-73.

21. Farrel DJ, Morrisey I, Rubies D, Robbins $M$, Felmingham D. A UK multicentre study of the antimicrobial susceptibility of bacterial pathogens causing UTI. J Infect. 2003;46:94-100.

22. Mohammed A, Mohammed S, Asad K. Etiology and antibiotic resistance patterns of communityacquired urinary tract infections in JNMC Hospital Aligarh, India. Ann Clin Microbiol Antimicrobial. 2007;6(4):1-7.

23. Das RN, Chandrashekhar TS, Joshi HS, Gurung M, Shrestha N, Shivananda PG. Frequency and susceptibility profile of pathogens causing urinary tract infections at a tertiary care hospital in western Nepal. Singapore Med J. 2006;47:281-5.

24. Nordenstam GR, Brandberg CA, Oden AS et al. Bacteriuria and mortality in an elderly population. $\mathrm{N}$ Engl J Med. 1986;314:52.

25. Tsunoda K, Goya N, Miyakaji Y, et al. Bacterial flora of the urinary tract and their drug sensitivity: 2 years clinical statistics in Sansskinkai Hara Hospital, Japan. Nishinihon J Urol.1979;41(2):337-45.

26. Okada K, Usui Y, Wantanabe R. Statistics studies on bacteria isolated from urinary tract infection (Report 6: Isolation rate and drug sensitivity from 1988 through 1989). Acta Urol Japonica.1994;40:175-85.

27. Obi CL, Tarupiwa A, Simango C. Scope of urinary pathogens isolated in the public Health Bacteriology Laboratory. Harare: Antibiotic susceptibility patterns of isolates and incidence of haemolytic bacteria. Central African J Med.1996;42(8):244-9. 
28. Gales AC, Sader HS, Jones RN. Urinary tract infection trends in Latin American hospitals: report from the SENTRY antimicrobial surveillance program (19972000). Diagnostic Microbiol Infect Dis. 2002;44:28999.

29. Ozeki S, Deguchi T, Yasuda M, Nakano M, Kawamura T, Nishino Y, Kawada Y. Development of a rapid assay for detecting gyrA mutations in Escherichia coli and determination of incidence of gyrA mutations in clinical strains isolated from patients with complicated urinary tract infections. J Clin Microbiol. 1997;35:2315-9.
30. Sulavik MC, Houseweart C, Cramer C, Jiwani N, Murgolo N, Greene J. Antibiotic Susceptibility Profiles of Escherichia coli Strains Lacking Multidrug Efflux Pump Genes. Antimicrobial Agents and Chemotherapy. 2001;45:1126-36.

31. Abubakar EM. Antimicrobial susceptibility pattern of pathogenic bacteria causing urinary tract infections at the Specialist Hospital, Yola, Adamawa state, Nigeria. J Clin Med Research. 2009;1(1):1-8.

32. Baral P, Neupane S, Marasini BP, Ghimire KR, Lekhak B, Shrestha B. High prevalence of multidrug resistance in bacterial uropathogenes from Kathmandu, Nepal [Internet]. 2012. Available from: http://creativecommons.org/licenses/by/2.0 